\title{
STUDI PENENTUAN DIFUSIVITAS PANAS MANGGA ARUMMANIS TERPROSES MINIMAL
}

\section{Determination of Thermal Diffusivity of Minimmaly Processed from Mango Arummanis}

\author{
Lamhot P. Manalu ${ }^{1}$, Amos Lukas ${ }^{1}$ dan Gustri Yeni ${ }^{2}$ \\ 1. Pusat Teknologi Agroindustri dan Pusat Audit Teknologi BPPTGd. 2 Lt. 17 dan Lt. 12 \\ Jl. Thamrin 8 Jakarta 10340. \\ e-mail: Ipmanalu@yahoo.com \\ 2. Balai Riset dan Standardisasi Industri Padang \\ Diterima : 17 September 2012, Revisi akhir: 14 November 2012
}

\begin{abstract}
ABSTRAK
Pada perancangan suatu sistem pengolahan hasil pertanian diperlukan pengetahuan tentang sifat-sifat panas suatu bahan diantaranya panas jenis, konduktivitas, dan difusivitas panas. Nilai-nilai tersebut untuk produk pertanian lokal sangat jarang ditemukan, sehingga dalam aplikasinya sering digunakan data sifat panas dari literatur luar yang belum tentu sesuai dan tepat dengan produk dalam negeri, hal ini dapat menyebabkan terjadinya bias dalam perhitungan dan perancangan. Studi ini bertujuan untuk menentukan sifat-sifat panas dari produk mangga arummanis terproses minimal. Hasil studi ini mendapatkan bahwa nilai panas konduktivitas panas mangga arummanis terproses minimal adalah $0.6058 \mathrm{~W} / \mathrm{m}^{\circ} \mathrm{C}$, sedangkan nilai difusivitas panasnya adalah $1.70 \times 10^{-7} \mathrm{~m}^{2} /$ detik.
\end{abstract}

Kata kunci : Sifat panas, konduktivitas, difusivitas panas, mangga

\section{ABSTRACT}

The important limitation in process design for agricultural products is the lack of information on their thermal properties. Although a lot of experimental data can be found, the variety of products and the differences in measurement method make limitation on the value of the available data, especially for Indonesian products. These data are required to get information about temperature change when product was processed like heating or cooling. It is worth to optimize efficiency of energy. The objective of this study was to predict thermal diffusivity and conductivity of minimmaly processed product of arummanis mangoes. The value was determined numerically with direct and indirect methods. The result showed that thermal conductivity was $0.6058 \mathrm{~W} / \mathrm{m}^{\circ} \mathrm{C}$ while thermal diffusivity was $1.70 \times 10^{-7} \mathrm{~m}^{2} / \mathrm{s}$ (direct method).

Keywords:Thermal properties, conductivity, thermal diffusivity, mango

\section{PENDAHULUAN}

Kesibukan kerja untuk meningkatkan prestasi dan pendapatan menyebabkan waktu yang tersedia diluar urusan pekerjaan semakin sempit. Hal ini membawa konsekuensi beralihnya pilihan masyarakat terhadap buah-buahan segar yang praktis dan cepat tersaji. Salah satu cara untuk memenuhi kebutuhan buahbuahan tersebut adalah dengan menghilangkan bagian-bagian yang tidak dapat dimakan dan proses meminimalkan ukuran (minimally processed), yaitu proses penanganan yang meliputi kegiatan pembersihan, pencucian, sortasi, pengupasan, dan pemotongan menjadi bagian-bagian yang lebih kecil dengan bentuk spesifik sesuai komoditas yang diproses.

Dengan adanya luka bekas pengupasan dan pemotongan menyebabkan meningkatnya proses respirasi dan metabolisme yang diikuti 
dengan cepat oleh proses kerusakan. Masalah lain yang dihadapi dari produk minimally processed adalah terjadinya perubahan fisiologis yang tidak diinginkan karena berkurangnya keutuhan sel produk akibat pengupasan dan pemotongan (Rolle dan Chims, 1987). Berkurangnya keutuhan sel tersebut mengakibatkan terjadinya peningkatan laju produksi etilen, peningkatan laju respirasi, degradasi membran lipid, reaksi pencoklatan dan laju penguapan air (Brecht, 1995). Keadaan ini mengakibatkan pendeknya masa simpan produk minimally processed. Selain itu, permukaan buah yang dipotong merupakan media tumbuh yang baik bagi mikroorganisme yang dapat membahayakan kesehatan. Oleh karena itu, sanitasi dalam pembuatan produk minimally processed baik peralatan, bahan, tempat maupun operatornya perlu diperhatikan (Hurst, 1995). Untuk itu diperlukan penanganan pasca proses pada produk minimally processed antara lain melalui penyimpanan pada suhu rendah (pendinginan).

Pendinginan merupakan suatu usaha untuk menurunkan dan mempertahankan suhu suatu bahan di bawah suhu lingkungan, namun masih berada diatas titik bekunya. Agar proses pendinginan berhasil, maka diperlukan kondisi pendinginan yang optimum dan sesuai dengan bahan yang didinginkan. Menurut Sweat (1986), perlu diketahui sifat-sifat panas (termofisik) buah-buahan seperti panas jenis, konduktivitas dan difusivitas panas dalam menganalisis masalah pendinginan serta penyimpanan buahbuahan yang menggunakan prinsip-prinsip pindah panas.

Sifat-sifat panas (thermal properties) bahan merupakan parameter penting yang dibutuhkan untuk menduga laju perubahan suhu bahan sehingga dapat ditentukan waktu optimum yang dibutuhkan dalam pengolahan, pengeringan, pendinginan atau penyimpanan (Mohsenin, 1980). Dengan mengetahui waktu optimum tersebut, selain dapat dihindarkan terjadinya kerusakan bahan juga dapat menghemat energi.

Mangga (Mangivera indica Linn) termasuk buah tropika yang banyak diusahakan oleh petani di pedesaan dengan berbagai jenis varietas. Jenis varietas yang mempunyai prospek dan nilai komersial tinggi adalah mangga Arummanis. Sebagai tanaman asli Indonesia, perkembangan mangga cukup pesat. Produk minimally processed buah mangga akan memiliki sifat segar, lebih prkatis dan dapat cepat tersaji, sehingga akan memberikan nilai tambah dan meingkatkan penjualan buah mangga (Wong et al., 1994).

Penelitian ini bertujuan untuk menentukan thermal properties buah mangga produk minimally processed yang mencakup nilai difusivitas panas secara tidak langsung dan menentukan nilai difusivitas panas dengan metode numerik.

\section{METODOLOGI PENELITIAN}

\section{Bahan dan Alat}

Penelitian dilakukan di Laboratorium Energi dan Elektrifikasi Pertanian FatetaIPB. Bahan yang digunakan adalah mangga arummanis. Alat-alat yang digunakan adalah conductivitymeter (Kemtherm QTM-D3), lemari pendingin (Ebara 3848), hybrid recorder (HR-2500E), termokopel CC, drying oven (Ikeda SS204D), timbangan digital (AND EK-1200A), kalorimeter, termometer, jangka sorong, gelas ukur.

Metode yang digunakan dalam menentukan sifat-sifat panas produk yang mencakup panas jenis, konduktivitas panas dan difusivitas panas adalah sebagai berikut.

\section{Penentuan Panas Jenis}

Panas jenis didefinisikan sebagai jumlah energi yang dibutuhkan oleh satu satuan berat bahan untuk menaikkan suhunya sebesar satu derajat (Holman, 1984). Besaran ini dipakai untuk menduga jumlah energi (Q) yang diperlukan bila suhu bahan berubah satu satuan $(\Delta \mathrm{T})$.

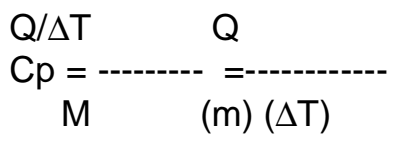


Siebel mengembangkan suatu persamaan untuk menghitung panas jenis bahan dengan membedakan pada dua kondisi yaitu pertama, kondisi diatas titik beku dan kedua, di bawah titik beku (Sweat, 1986), masing-masing sebagai berikut :

$$
\begin{aligned}
& C p=4.1868(0.008 M+0.20) \\
& C p=4.1868(0.003 M+0.20)
\end{aligned}
$$

dimana $\mathrm{M}$ adalah persentase kadar air (basis basah).

Metode yang diajukan Charm dalam menghitung panas jenis turut mempertimbangkan kandungan lemak bahan (Heldman \& Singh, 1981). Metode ini cukup baik terutama bagi bahan-bahan yang kandungan lemaknya cukup tinggi.

$$
\mathrm{Cp}=4.1868\left(0.5 X_{f}+0.33 X_{s}+X_{m}\right)
$$

dimana $\mathrm{X}_{\mathrm{f}}$ adalah fraksi lemak, $\mathrm{X}_{\mathrm{s}}$ adalah fraksi padatan dan $X_{m}$ adalah fraksi air dalam bahan.

Selain dua metode diatas, panas jenis dapat ditentukan dengan metode campuran (method of mixtures) (Mohsenin, 1980). Metode ini banyak dipakai karena caranya sederhana yaitu dengan memasukkan bahan yang sudah diketahui masanya $\left(\mathrm{W}_{\mathrm{S}}\right)$ kedalam kalorimeter berisi air yang sudah diketahui berat $\left(\mathrm{W}_{\mathrm{W}}\right)$ dan kapasitas panasnya $\left(\mathrm{C}_{\mathrm{w}}\right)$.

Pengukuran dengan metode campuran didasarkan pada hukum keseimbangan panas dalam kalorimeter yang secara matematis ditulis sebagai berikut (Mohsenin, 1980) :

$$
\begin{aligned}
& C_{S} \cdot W_{S}\left(T_{a}-T_{e}\right)=C_{w} \cdot W_{w}\left(T_{e}-T_{0}\right)+ \\
& C_{c} \cdot W_{c}\left(T_{e}-T_{0}\right)(5)
\end{aligned}
$$

Panas jenis dan masa kalorimeter dianggap konstan sehingga perkaliannya merupakan kapasitas panas kalorimeter. Persamaan di atas dapat ditulis sebagai berikut (Mohsenin, 1980):

$$
C_{S}=\frac{C_{W} \cdot W_{W}\left(T_{e}-T_{0}\right)+H_{C}\left(T_{e}-T_{0}\right)}{W_{S}\left(T_{a}-T_{e}\right)}
$$

Kapasitas panas kalorimeter $\left(\mathrm{H}_{\mathrm{C}}\right)$ dapat ditentukan dengan mencampur sejumlah air yang berbeda suhu awalnya dalam kalorimeter hingga dicapai suhu keseimbangan. Persamaan untuk menetukan kapasitas panas $\mathrm{H}_{\mathrm{c}}$ (Mohsenin, 1980):

$$
H_{C}=\frac{C_{h} \cdot W_{h}\left(T_{a}-T_{e}\right)-C_{C} \cdot W_{C}\left(T_{e}-T_{0}\right)}{\left(T_{e}-T_{0}\right)}
$$

dimana :

$\mathrm{Hc}=$ kapasitas panas kalorimeter, $\mathrm{kJ} /{ }^{\circ} \mathrm{C}$

$\mathrm{Wh}=$ massa air panas, $\mathrm{kg}$

$\mathrm{Wc}=$ massa air dingin, $\mathrm{kg}$

$\mathrm{Ta}=$ suhu awal air panas, ${ }^{\circ} \mathrm{C}$

$\mathrm{Te}=$ suhu keseimbangan, ${ }^{\circ} \mathrm{C}$

To = suhu awal air dingin, ${ }^{\circ} \mathrm{C}$

$\mathrm{Cs}=$ panas jenis bahan, $\mathrm{kJ} / \mathrm{kg}{ }^{\circ} \mathrm{C}$

$\mathrm{Ws}=$ massa bahan, $\mathrm{kg}$

$\mathrm{Cc}=$ panas jenis kalorimeter, $\mathrm{kJ} / \mathrm{kg}{ }^{\circ} \mathrm{C}$

\section{Penentuan Konduktivitas Panas}

Konduktivitas panas adalah sifat termal suatu benda untuk merambatkan panas dalam suatu unit waktu melalui luas penampang tertentu yang diakibatkan oleh adanya perbedaan suhu. Untuk bahan hayati, besarnya nilai konduktivitas panas (k) banyak dipengaruhi oleh beberapa faktor seperti struktur sel/fisik, komposisi kimia bahan, dan kandungan air. Variasi nilai konduktivitas panas bahan hayati lebih besar dibandingkan bahan non hayati (Chowdary, 1988).

Dalam percobaan ini konduktivitas panas mangga diukur langsung dengan menggunakan alat conductivitymeter, sedangkan secara tidak langsung konduktivitas panasnya dihitung dengan persamaan (Sweat, 1986) berikut :

$$
k=0.148+0.00493 M
$$

dimana $\mathrm{M}$ adalah kadar air mangga (\%bb.).

\section{Penentuan Difusivitas Panas}

Difusivitas panas dapat diartikan sebagai laju pada saat panas terdifusi keluar dari bahan. Distribusi suhu pada suatu bahan dalam kondisi tidak mantap 
telah dirumuskan oleh persamaan umum Fourier sebagai berikut (Bird et al., 1960) :

$\partial \mathrm{T} / \partial \mathrm{t}=\alpha \nabla^{2} \mathrm{~T}$

dimana $\mathrm{T}$ adalah suhu pada titik tertentu (pada koordinat $x, y$ dan $z$ ), $t$ adalah waktu dan $\alpha$ adalah koefisien difusivitas panas.

Dengan mengasumsikan mangga berbentuk silinder dan perpindahan panas merata ke arah radial, suhu awal di setiap titik dianggap seragam, kadar air tetap dan tidak terjadi penyusutan, persamaan (8) dapat ditulis sebagai berikut (Carslaw \& Jaeger, 1971) :

$$
\begin{aligned}
& \partial \mathrm{T} \quad \partial \mathrm{T}^{2} \quad 1 \quad \partial \mathrm{T} \\
& \partial \mathrm{t}^{---}=\alpha\left(----\mathrm{r}^{2}+----{ }^{2}\right)
\end{aligned}
$$

Persamaan (10) di atas didiskritisasi memakai metode numerik beda hingga sehingga diperoleh :

$$
\begin{aligned}
& T_{i}^{j+1}-T_{i}^{j}=S\left[\left\{T_{i+1}^{j}-2 T_{i-1}^{j}+\underset{j}{j}\right\}+\right.
\end{aligned}
$$

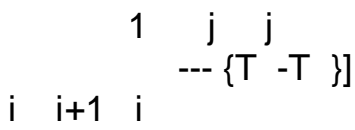

Selanjutnya nilai S dihitung dengan metode kuadrat terkecil (least square method) dan nilai $\alpha$ dihitung dengan persamaan (12).

$$
\stackrel{\alpha \Delta t}{S=\frac{-----}{(\Delta r)^{2}}<0.5}
$$

Dalam hubungannya dengan sifat termofisik bahan lainnya, nilai difusivitas panas berbanding lurus dengan konduktivitas panas $(k)$ dan berbanding terbalik dengan panas jenis (Cp) dan kerapatan bahan $(\rho)$ tersebut.

Hubungan yang digambarkan pada persamaan (13) dapat dipakai untuk menentukan difusivitas panas yang dikenal sebagai metode tidak langsung.

$$
\alpha=\frac{k}{\text { Cp } \rho}
$$

Penentuan difusifitas panas secara langsung dengan metoda numerik dilakukan dengan menggunakan data distribusi perubahan suhu mangga selama pendinginan. Data perubahan suhu mangga diambil dari tiga titik pengukuran. Titik pertama merupakan titik pusat sedangkan titik kedua dan ketiga diukur berjarak $\Delta r$ dan $2^{*} \Delta r$ kearah radial. Pengukuran dihentikan bila suhu disetiap titik pengamatan sudah relatif seragam.

\section{HASIL DAN PEMBAHASAN}

Pada Tabel 1 dapat dilihat nilai pengukuran konduktivitas panas mangga arummanis minimally processed yang diperoleh dengan menggunakan alat thermal conductivity meter. Konduktivitas panas rata-rata adalah $0.6058 \mathrm{~W} / \mathrm{m}^{\circ} \mathrm{C}$ pada kisaran suhu $33-43{ }^{\circ} \mathrm{C}$. Nilai ini lebih kecil dari konduktivitas panas mangga utuh sebesar $0.6923 \mathrm{~W} / \mathrm{m}^{\circ} \mathrm{C}$ (Manalu, 2003).

Tabel 1. Hasil pengukuran konduktivitas panas $(\mathrm{k})$ mangga arummanis minimally processed

\begin{tabular}{|c|c|}
\hline Ulangan & $\mathrm{k}\left(\mathrm{W} / \mathrm{m}^{\circ} \mathrm{C}\right)$ \\
\hline 1 & 0.5522 \\
2 & 0.6587 \\
3 & 0.6560 \\
4 & 0.5564 \\
5 & 0.6055 \\
\hline Rataan & 0.6058 \\
\hline SD & 0.0516 \\
\hline
\end{tabular}

Data pengukuran dan hasil perhitungan massa jenis mangga disajikan pada Tabel 2, Berdasarkan hasil perhitungan pada tabel tersebut diketahui massa jenis rata-rata mangga arummanis minimally processed adalah $0,9872 \mathrm{~g} / \mathrm{cm} 3$ atau $987.2 \mathrm{~kg} / \mathrm{m}^{3}$.

Panas jenis mangga arummanis minimally processed pada studi ini ditentukan dengan metode Siebel (persamaan 2) dan metode campuran (persamaan 6). Hasil perhitungan panas jenis rata-rata mangga arummanis minimally processed dengan metode Siebel $\left.\begin{array}{lllll}\text { adalah } & 3.6187 & \mathrm{~kJ} / \mathrm{kg}^{\circ} \mathrm{C} & (\text { Tabel } & 3\end{array}\right)$, 
sedangkan dengan metode campuran $3.6134 \mathrm{~kJ} / \mathrm{kg}^{\circ} \mathrm{C}$ (Tabel 4). Sedangkan untuk mangga utuh nilainya masung-masing adalah $3.6040 \mathrm{~kJ} / \mathrm{kg}^{\circ} \mathrm{C}$ dan $3.5120 \mathrm{~kJ} / \mathrm{kg}^{\circ} \mathrm{C}$ (Manalu, 2003)

Tabel 2. Data fisik dan perhitungan massa jenis mangga arummanis minimally processed

\begin{tabular}{|c|c|c|c|c|c|c|}
\hline \multirow{2}{*}{ Ulangan } & \multicolumn{3}{|c|}{ Karakteristik Dimensi (mm) } & Massa & Volume & Massa Jenis \\
\hline & Panjang & Tinggi & Lebar & (g) & $\left.\mathrm{cm}^{3}\right)$ & $\left(\mathrm{g} / \mathrm{cm}^{3}\right)$ \\
\hline 1 & 75.05 & 26.70 & 16.65 & 31.20 & 32.00 & 0.9750 \\
\hline 2 & 75.40 & 20.40 & 19.45 & 31.50 & 32.00 & 0.9844 \\
\hline 3 & 70.00 & 17.95 & 19.95 & 28.00 & 29.00 & 0.9655 \\
\hline 4 & 63.00 & 14.34 & 18.20 & 26.20 & 27.00 & 0.9703 \\
\hline 5 & 49.00 & 12.30 & 17.40 & 15.40 & 16.00 & 0.9625 \\
\hline Rataan & & & & & & 0.9872 \\
\hline SD & & & & & & 0.0086 \\
\hline
\end{tabular}

Tabel 3. Hasil pengukuran kadar air dan perhitungan panas jenis mangga arummanis dengan Metode Siebel

\begin{tabular}{|c|c|c|c|}
\hline Ulangan & Kadar air (\% bk.) & Kadar air (\% bb.) & Panas jenis $(\mathrm{kJ} / \mathrm{kgC})$ \\
\hline 1 & 481.3953 & 82.80 & 3.6107 \\
\hline 2 & 443.4783 & 81.60 & 3.57 .05 \\
\hline 3 & 541.0256 & 84.40 & 3.6642 \\
\hline 4 & 517.2840 & 83.80 & 3.0681 \\
\hline 5 & 474.7126 & 82.60 & 3.6040 \\
\hline Rataan & 474.7126 & 82.60 & 3.6187 \\
\hline SD & & & 0.0365 \\
\hline
\end{tabular}

Panas jenis mangga makin tinggi bila kadar airnya makin tinggi. Hal ini menunjukkan adanya korelasi positif antara panas jenis dan kadar air karena panas jenis air lebih tinggi dari padatannya. Dengan demikian dapat dimengerti bahwa metode Siebel cukup baik diterapkan untuk bahan yang mengandung kadar air tinggi.

Penentuan difusivitas panas mangga arummanis minimally processed secara tidak langsung (persamaan 13) dihitung dengan menggunakan nilai panas jenis mangga dari persamaan Siebel.
Nilai difusivitas panas mangga arummanis minimally processed yang didapatkan adalah $1.70 \times 10^{-7} \mathrm{~m}^{2} /$ det. Sebagaimana nilai konduktivitas panas, nilai difusivitas panas mangga arummanis minimally processed ini lebih kecil dari mangga utuh yang sebesar $1.88 \times 10^{-7}$ $\mathrm{m}^{2} /$ det (Manalu, 2003). Mohsenin (1980) melaporkan bahwa difusifitas panas mangga adalah $1.264 \times 10^{-7} \mathrm{~m}^{2} /$ det. Perbedaan ini diduga disebabkan oleh perbedaan kandungan komposisi dan varietas bahan serta metoda yang digunakan. 
Tabel 4. Data pengukuran dan hasil perhitungan panas jenis mangga arummanis menggunakan Metode Campuran

\begin{tabular}{|c|c|c|c|c|}
\hline No. & Keterangan & Simbol & Ulangan 1 & Ulangan 2 \\
\hline $\begin{array}{l}1 \\
2 \\
3 \\
4 \\
5 \\
6 \\
7\end{array}$ & $\begin{array}{l}\text { Massa air dingin }(\mathrm{g}) \\
\text { Massa mangga }(\mathrm{g}) \\
\text { Suhu mangga awal }\left({ }^{\circ} \mathrm{C}\right) \\
\text { Suhu keseimbangan }\left({ }^{\circ} \mathrm{C}\right) \\
\text { Suhu air dingin awal }\left({ }^{\circ} \mathrm{C}\right) \\
\text { Panas jenis air }\left(\mathrm{kJ} / \mathrm{kg}^{\circ} \mathrm{C}\right) \\
\text { Kapasitas Panas Kalori-meter }(\mathrm{kJ} / \mathrm{kg})\end{array}$ & $\begin{array}{l}\text { Ww } \\
\text { Ws } \\
\text { Ta } \\
\text { Te } \\
\text { To } \\
\text { Cw } \\
\text { Hc }\end{array}$ & $\begin{array}{l}180 \\
30 \\
28.2 \\
12.5 \\
10.5 \\
4.1868 \\
89.1184 \\
\end{array}$ & $\begin{array}{l}180 \\
30 \\
28.0 \\
12.6 \\
10.6 \\
4.1868 \\
89.1184 \\
\end{array}$ \\
\hline & Panas jenis bahan $\left(\mathrm{kJ} / \mathrm{kg}^{\circ} \mathrm{C}\right)$ & $\mathrm{Cp}$ & 3.5785 & 3.6482 \\
\hline & Rata-rata $\mathrm{Cp}$ mangga $\left(\mathrm{kJ} / \mathrm{kg}^{\circ} \mathrm{C}\right)$ & 3.6134 & & \\
\hline
\end{tabular}

\section{KESIMPULAN}

1. Panas jenis buah mangga arummanis $3.6134 \mathrm{~kJ} / \mathrm{kg}^{\circ} \mathrm{C}$ pada selang kadar air 81.6 - 84.4\%. Konduktivitas panasnya $0.6058 \mathrm{~W} / \mathrm{m}^{\circ} \mathrm{K}$ dan masa jenisnya (density) $987.2 \mathrm{~kg} / \mathrm{m}^{3}$.

2. Nilai difusivitas panas mangga arummanis minimally processedhasil kajian ini adalah $1.70 \times 10^{-7} \mathrm{~m}^{2} /$ detik.

\section{DAFTAR PUSTAKA}

Bird, R.B., W.E. Stewart and E.N. Lightfoot. 1960. Transport Phenomena. John Wiley \& Sons, New York.

Brecht, J. K. 1995. Physiology of lightly processed fruits and vegetables. J. Hort. Sci. 30 (1): 18 - 21.

Burn, J. K. 1995. Lightly processed fruits and vegetables. Introduction to the

colloquium. J. Hort. Sci. 30 (1) : 14.

Carslaw, H. S. and J. C. Jaeger. 1971. Conduction of Heat and Solids. Oxford at the Clarendon Press.

Chowdary, T.P. 1988. Thermal Properties of Mangoes. Master of Eng. Thesis, AIT, Bangkok.

Couture, R., M. I. Cantwell, D. Ke and M. E. Saltveit Jr. 1993. Phsiology Attributes Related to Quality Attributes and Storage Life of Minimally Processed Lettuce. J. Hort. Science 28 (7) : $723-$ 725.
Heldman, D.R. and R.P. Singh. 1981. Food Process Engineering, The AVI Pub. Co. Inc., Westport, Connecticut.

Holman, J. P. 1984. Perpindahan kalor. Terjemahan. Penerbit Erlangga, Jakarta.

Hurst, W. C. 1995. Sanitation of ligthly processed fruits and vegetables. J. Hort. Sci. 30 (1) : $22-24$

Manalu, L.P. 2003. Studi Sifat-sifat Panas (Thermal Properties) Mangga Arummanis. Jurnal Sains dan Teknologi Indonesia, BPPT, Vol. 5, No. 3 Desember 2003, p. 121-126.

Mohsenin, N.N. 1980. Thermal Properties of Foods and Agricultural Materials. Gordon and Breach Science Publishers, New York.

Pantastico, EB., TK. Chattopadhyay and H. Subramanyam. 1975, Storage and Commercial Storage Operation. In Pantastico (Ed.), Postharvest Physiology, Handling and Utilization of Tropical and Subtropical Fruits and Vegetables, The AVI Pub. Co. Inc., Westport, Connecticut.

Sapers, G. M. , R. E. Miller, F. C. Miller, P. H. Cooke and S. W. Choi. 1994. Enzymatic browning control in minimally processed mushrooms. J. Food Sci. 59 (5) : 1042 - 1047.

Sears, 1950. Mechanic, Heat and Sound, Addison Wessley Pub. Co. Inc., Massachusetts. 
Sweat, V. E. 1986. Thermal properties of foods. In Engineering properties of foods. M. A. Rao and S. S. H. Rizvi (ed). Marcel Dekker. New York.

Toledo, R. T. 1980. Fundamentals of food process engineering. The AVI Pub. Co. Inc. Wesport, Connecticut.
Wong, D. W. S., W. M. Camirand, and A. E. Pavlath. 1994. Development of edible coating for minimally processed fruits and vegetables, p. $65-88$. In Krochta, J. M., E. A. Baldwin and M. O. Nisperos - Carriedo. Edible coating and films to improve food quality. Technomic Pub. Co. Inc., Pennsylvania. 